\title{
Тенденции и варианты этнической социализации подростков
}

\section{Соелма Б. Дагбаева}

Забайкальский государственный университет, г. Чита, Российская Федерация E-mail: soela@bk.ru

\begin{abstract}
Аннотация
Ввеление. Во введении статьи автором обоснована актуальность исслеАОвания особенностей этнической социализации подростков в современных социокультурных условиях. Цель исследования заключалась в изучении особенностей этнической социализации полростков и вылелении на их основе вариантов этнической социализации. При этом этническую социализацию ^ичности автор рассматривает как процесс, результатами которого являются тип этнической илентичности, ценностные ориентации и толерантность. Новизна исследования состоит в вылелении трех вариантов этнической социализации испытуемых, обозначенных автором как успешная, незавершенная и этническая Аесоциализация.
\end{abstract}

Методы. Описывается использованный психодиагностический комп^екс, сфоормированный в соответствии с критериями и показателями этнической социализации. В исследовании были использованы: экспресс-опросник «ИнАекс толерантности» Г.У. СолАатовой и Ар., «Шкала социальной Аистанции» Э. Богардуса, методика «Типы этнической иАентичности» Г.У. СолАатовой и С.В. Рыжовой, Аиагностический тест отношений Г.У. СолАатовой, опросник инАивиАуальных ценностей Ш. Шварца. Математико-статистическая обработка проведена с помощью U-критерия Манна - Уитни. Выборку исслеАования составили 250 школьников г. Чита в возрасте от 12 АО 14 лет.

Результаты. ИсслеАование выяви^о тенАенции и риски в этнической социализации полростков, проявляющиеся в наличии негативных этнических стереотипов, снижении ценностей универсализма и толерантности, размывании этнической иАентичности, этнической избирательности.

ОбсужАение результатов. Полученные данные позволили вылелить три группы поАростков, в зависимости от их типа этнической иАентичности, уровня толерантности, показателей социальной Аистанции, ценностных ориентаций и характера этнических стереотипов, характеризующие три варианта этнической социализации.

\section{КАючевые слова}

социализация, этническая иАентичность, этническая социализация поАростков, 


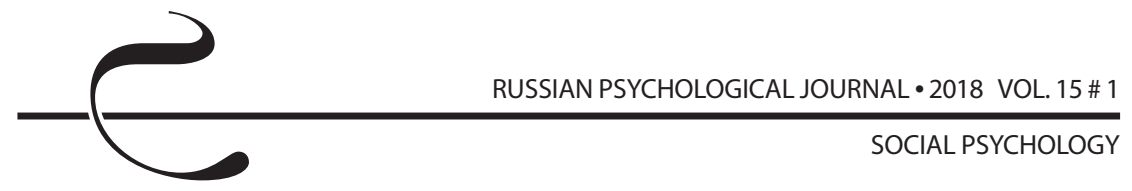

ценностные ориентации, толерантность, стереотипы, социальная Аистанция, тенденции этнической социализации, варианты этнической социализации

\section{Основные положения}

- этническая социализация характеризуется как процесс вхожАения инАивиАа в полиэтническое общество, в результате которого фрормируются определенный тип этнической иАентичности, этническая толерантность, ценностные ориентации;

- вылеляются три варианта этнической социализации полростков;

- при успешной этнической социализации отмечаются позитивная этническая илентичность, развитая толерантность, ценностное отношение к этнокультурным различиям;

- при незавершенной этнической социализации наблюАаются этническая инАидрорерентность, снижение толерантности и избирательная толерантность;

- при этнической Аесоциализации наблюАаются гиперболизация этнической иАентичности, интолерантность и этническая преАубежАенность.

\section{Благодарности}

Данная работа выполнена в рамках гранта № 245-ГР Совета по научной и инновационной деятельности Забайкальского государственного университета.

\section{Для цитирования}

Дагбаева С.Б. Тенденции и варианты этнической социализации подростков // Российский психологический журнал. - 2018. - Т. 15, № 1. - С. 140-156. DOI: 10.21702/rpj.2018.1.7

Материалы статьи получены 16.06.2017

UDC 159.9.072

DOI: 10.21702/rpj.2018.1.7

\section{Tendencies and Types of Ethnic Socialization Among Adolescents}

\section{Soelma B. Dagbaeva}

Transbaikal State University, Chita, Russian Federation

E-mail: soela@bk.ru

\section{Abstract}

Introduction. Adolescents' ethnic socialization is a topical issue in modern sociocultural conditions. Ethnic socialization determines the type of ethnic identity, value orientations and tolerance. The present study deals with characteristics of adolescents' ethnic socialization and reveals its types. The paper presents an innovative view of 
ethnic socialization types, which may be grouped as follows: (a) successful type, (b) incomplete type and (c) ethnic desocialization.

Methods. The study employed the following techniques (a) the Tolerance Index express questionnaire by G.U. Soldatova et al.; (b) Bogardus Social Distance Scale; (c) Types of Ethnic Identity technique by G.U. Soldatova and S.V. Ryzhova; (d) Relationships Diagnostic Test by G.U. Soldatova; (e) The Portrait Values Questionnaire by Schwartz et al. The Mann-Whitney $U$ test was a method for mathematical and statistical data processing. The study involved 250 school students from Chita at the age from 12 to 14 years.

Results. The study revealed the following tendencies and risks in the adolescents' ethnic socialization: (a) negative ethnic stereotypes; (b) decrease in tolerance and universalism values; (c) ethnic selectivity; and (d) blurring ethnic identity.

Discussion. The findings suggest that depending on the type of ethnic socialization, which includes the type of ethnic identity, tolerance level, characteristics of social distance, value orientations, and ethnic stereotypes, adolescents fall into one of three groups.

\section{Keywords}

socialization, ethnic identity, adolescents' ethnic socialization, value orientations, tolerance, stereotypes, social distance, ethnic socialization tendencies, ethnic socialization types

\section{Highlights}

- Ethnic socialization is the process of an individual's integration into a multi-ethnic society, which determines his/her value orientations, tolerance, and the type of ethnic identity.

- There are three types of adolescents' ethnic socialization.

- Positive ethnic identity, high level of tolerance, and also value attitude to ethnic and cultural differences are the characteristics of successful ethnic socialization.

- Ethnic indifference, decreased tolerance, and selective tolerance are the characteristics of incomplete ethnic socialization.

- Overstatement of ethnic identity, intolerance, and ethnic bias are the characteristics of ethnic desocialization.

\section{Acknowledgments}

This research was supported by a grant from the Council for Science and Innovation of Transbaikal State University (project no. 245-ГP).

\section{For citation}

Dagbaeva S. B. Tendencies and Types of Ethnic Socialization Among Adolescents. Rossiiskii psikhologicheskii zhurnal - Russian Psychological Journal, 2018, V. 15, no. 1, pp. 140-156 (in Russian). DOI: 10.21702/rpj.2018.1.7 


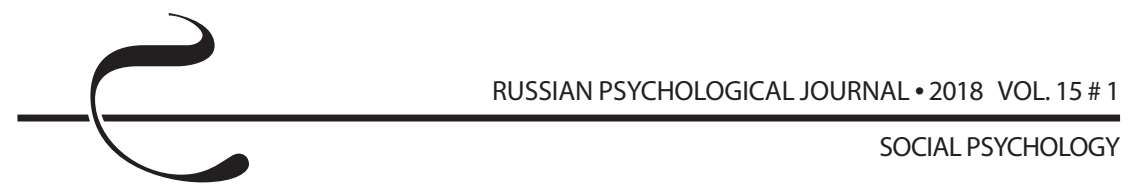

\section{Введение}

Научное обсуждение проблемы этнической социализации подростков является одним из актуальных направлений в современных исследованиях. Этническая социализация может определяться как процесс вхождения индивида в полиэтническое общество, в результате которого формируются тип этнической идентичности, стереотипы, толерантность, ценностные ориентации и т. д. Особенно интенсивно этот процесс протекает в подростковом возрасте. В этот период происходит переход от детства к взрослости, и все стороны психики подвергаются качественной перестройке [1].

Важность подросткового периода для становления этнической идентичности, ценностных ориентаций и толерантности, рассматриваемых в качестве показателей этнической социализации, подчеркивается в трудах как отечественных исследователей Е.П. Белинской [2], Т.Г. Стефаненко [3], Г.У. Солдатовой [4], Ф.А. Темировой [5], С.Н. Федоровой [6], В.Ю. Хотинец [7, 8], А. В. Гришиной и С.Л. Лунина [9] и т. д., так и зарубежных ученых M. Bennett [10], C. Brown, W. Ling [11], A.Y. Chung [12], A. Csizmadia, A. Rollins, J.P. Kaneakua [13], M. M. Hernandez, R.D. Conger, R.W. Robins, K. B. Bacher, K.F. Widaman [14] и др.

В подростковом возрасте происходят консолидация усвоенных образцов социального поведения и самохарактеристик, расширение репертуара социальных ролей, установление баланса между зависимостью и независимостью, развитие системы ценностных ориентаций и т. д. [2]. Центральным моментом является «обретение идентичности», которому предшествует конфликт между индивидуализацией и размыванием идентичности, разрешаемый как в сторону позитивной, гармоничной Я-концепции, так и в сторону негативных изменений, неуверенности, непонимания себя, «идентификационной спутанности» или, другими словами, диффузной идентичности [15].

Отличительной характеристикой подросткового возраста является переход самосознания на качественно новый уровень, способствующий конструированию этнического мировоззрения [16, 17, 18, 19]. В зависимости от степени осознания себя в качестве представителя этнической группы и члена общества, сформированности позитивного образа своей и других этнических групп, уровня усвоения социальных норм и ценностей в качестве внутренних регуляторов поведения, индивид характеризуется принятием или непринятием этнического многообразия [20, 21, 22]. При этом главным признаком принятия личностью этнокультурного многообразия является положительное отношение к представителям других этнических групп при позитивном отношении к своему народу [23, 24, 25, 26]. 
В настоящее время исследователи отмечают ряд негативных тенденций, характеризующих современных подростков: обеднение и ограничение общения со сверстниками, рост явлений одиночества, отвержения, низкий уровень коммуникативной компетентности и т. д. [27, 28, 29]. В связи с этим особое внимание в нашем исследовании уделено этнической социализации подростков. Именно в данный период происходит индивидуализация этнокультурного опыта, сопровождающаяся становлением реализованной этнической идентичности, системы ценностных ориентаций и толерантности. Основными рисками этнической социализации в этот период являются: риск рассогласования системы ценностных ориентаций, размывания и трансформации этнической идентичности по негативным сценариям, становления интолерантности. Основываясь на изложенных выше теоретических положениях, мы провели эмпирическое исследование особенностей этнической социализации подростков.

\section{Методы}

Целью исследования явилось изучение особенностей этнической социализации подростков и выделение на их основе вариантов этнической социализации.

Гипотеза исследования состояла в следующем: в современных условиях этническая социализация подростков характеризуется определенными тенденциями, в числе которых трансформация этнической идентичности по негативному сценарию, недостаточный уровень толерантности, выраженная социальная дистанция к другим этническим группам, наличие негативных этнических стереотипов, снижение ценностей универсализма. Основываясь на анализе особенностей этнической социализации испытуемых, можно выделить варианты этнической социализации подростков.

Методологическую основу исследования составил культурно-исторический подход, согласно которому социализация интерпретируется как процесс вхождения в человеческую культуру, а этническая социализация понимается как интеграция индивида в полиэтническое общество.

Для исследования показателей этнической социализации подростков, в качестве которых выступают уровень толерантности, социальная дистанция, тип этнической идентичности, ценностные ориентации, использованы следующие методики: экспресс-опросник «Индекс толерантности» Г. У. Солдатовой и др.; шкала социальной дистанции Э. Богардуса; методика «Типы этнической идентичности» Г. У. Солдатовой и С.В. Рыжовой; диагностический тест отношений Г. У. Солдатовой; опросник индивидуальных ценностей Ш. Шварца (перевод Н.М. Лебедевой).

Выборку исследования составили обучающиеся средних общеобразовательных школ г. Чита в возрасте от 12 до 14 лет в количестве 250 человек, 


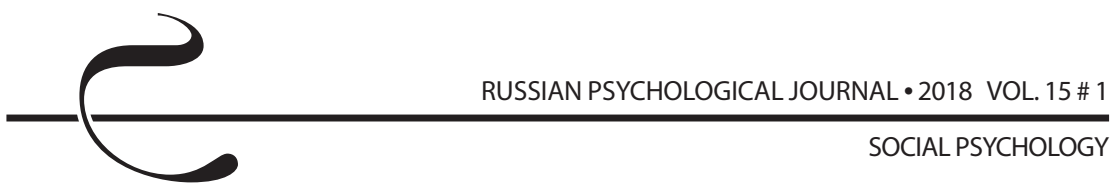

представляющие русскую культуру. Выборка была сбалансирована по полу, возрасту, социальному положению.

\section{Результаты}

Исследование социальной дистанции подростков по отношению к различным этническим группам с помощью методики Э. Богардуса показало, что присутствует избирательное отношение подростков к различным этническим группам. Обнаружена выраженная социальная дистанция по отношению к китайцам $(5,13)$, татарам $(5,04)$, узбекам $(4,78)$, азербайджанцам $(4,58)$. Средняя социальная дистанция, или готовность принять представителя другой этнической группы как коллегу и соседа, выявлена по отношению к таким народам, как белорусы $(3,92)$, армяне $(3,78)$, буряты $(3,45)$. Наиболее близкими для испытуемых являются русские (дистанция 1,2), которых желают видеть как друга и близкого родственника.

Исследование этнических стереотипов подростков с помощью методики «Диагностический тест отношений» Г.У. Солдатовой показало, что оценка подростками себя составляет 0,22, идеала - 0,29, оценка представителей других этнических групп - 0,12; оценка членов своей этнической группы на порядок выше и составляет 0,21. При этом представители иных национальностей оценивались зачастую негативно.

Как показала диагностика особенностей этнической идентичности подростков с помощью соответствующей методики, предложенной Г.У. Солдатовой и С.В. Рыжовой, у испытуемых преобладает позитивный тип этнической идентичности $(15,9)$. При этом наблюдается склонность к этнической индифферентности $(11,7)$ и этнофанатизму $(10,4)$. Наименее выражены этноэгоизм $(8,7)$, этноизоляционизм $(8,1)$ и этнонигилизм $(6,3)$.

Изучение ценностных ориентаций подростков с помощью опросника индивидуальных ценностей Ш. Шварца показало, что наиболее значимыми для испытуемых являются ценности безопасности $(5,08)$, включая личную безопасность, безопасность родственников и близких людей, общества и страны в целом. В основе данной ценности - потребность в определенности и предсказуемости мира, что является достаточно актуальной потребностью в условиях нарастающей изменчивости мира. На втором месте находятся ценности конформности $(5,06)$, обусловленные потребностью в сдерживании и предотвращении действий и побуждений, которые могут навредить другим. Далее идут: благожелательность $(5,03)$ - благополучие друзей и знакомых; самостоятельность $(4,71)$ не только в деятельности, но в мыслях; достижения $(4,61)$ - важность личного успеха, ценность социального одобрения; универсализм $(4,44)$ - равенство всех людей, толерантность; стимуляции $(4,35)$ - разнообразная активная жизнь. В числе наименее значимых 
ценностей, наряду с гедонизмом $(3,72)$ и властью $(2,88)$, подростки отмечают традиции $(3,95)$, выражающие стремление к сохранению обычаев, их уважение, принятие и признание идей, существующих в культуре и религии, отражающих их уникальность.

Изучение уровня толерантности подростков с помощью методики «Индекс толерантности» (Г.У. Солдатовой и др.) показало у большинства опрошенных (80\%) средний уровень развития толерантности, который характеризуется неустойчивой позицией и избирательностью в проявлениях толерантности по отношению к Другим, в зависимости от ситуации. Низкий уровень толерантности, т. е. нетерпимое отношение к Другим, продемонстрировали $12 \%$ опрошенных. Высокий уровень толерантности, а именное уважение и принятие различий, характерен только для $8 \%$ респондентов. В целом, средний индекс толерантности по группе составил 80,6.

Далее мы сопоставили данные по использованным методикам у испытуемых с разными уровнями толерантности (высоким - группа I, средним - группа II, низким - группа III). Результаты сравнительного анализа представлены в таблице 1.

Таблица 1. Варианты этнической социализации подростков

Table 1. Types of ethnic socialization among adolescents

\begin{tabular}{|c|c|c|c|c|}
\hline \multirow{2}{*}{$\begin{array}{c}\text { Критерии } \\
\text { Criteria }\end{array}$} & \multirow{2}{*}{$\begin{array}{c}\text { Показатели } \\
\text { Characteristics }\end{array}$} & \multicolumn{3}{|c|}{$\begin{array}{l}\text { Средние значения } \\
\text { Mean Scores }\end{array}$} \\
\hline & & $I$ & II & III \\
\hline $\begin{array}{l}\text { Толерантность } \\
\text { Tolerance }\end{array}$ & $\begin{array}{l}\text { ИнАекс толерантности } \\
\text { Tolerance index }\end{array}$ & 105,13 & 80,26 & 55,5 \\
\hline \multirow{4}{*}{$\begin{array}{l}\text { Стереотипы } \\
\text { Stereotypes }\end{array}$} & $\begin{array}{l}\text { Оценка себя (A1) } \\
\text { Self-appraisal (D1) }\end{array}$ & 0,31 & 0,21 & 0,18 \\
\hline & $\begin{array}{l}\text { Оценка илеала (A2) } \\
\text { Appraisal of an ideal (D2) }\end{array}$ & 0,32 & 0,3 & 0,29 \\
\hline & $\begin{array}{l}\text { Типичный представитель Сво- } \\
\text { ей национальности (АЗ) } \\
\text { A typical representative of his/ } \\
\text { her own nationality (D3) }\end{array}$ & 0,21 & 0,18 & 0,1 \\
\hline & $\begin{array}{l}\text { Типичный преАставитель Ару- } \\
\text { гой национальности }(\triangle 4) \\
\text { A typical representative of an- } \\
\text { other nationality (D4) }\end{array}$ & $0,16^{* *}$ & 0,11 & $-0,02^{* *}$ \\
\hline
\end{tabular}




\begin{tabular}{|c|c|c|c|c|}
\hline \multirow{2}{*}{$\begin{array}{l}\text { Критерии } \\
\text { Criteria }\end{array}$} & \multirow{2}{*}{$\begin{array}{c}\text { Показатели } \\
\text { Characteristics }\end{array}$} & \multicolumn{3}{|c|}{$\begin{array}{c}\text { Средние значения } \\
\text { Mean Scores }\end{array}$} \\
\hline & & $I$ & II & III \\
\hline $\begin{array}{l}\text { Социальная } \\
\text { Аистанция } \\
\text { Social distance }\end{array}$ & $\begin{array}{l}\text { Аругие этнические группы } \\
\text { в целом } \\
\text { Other ethnic groups }\end{array}$ & 3,5 & 4,2 & 4,4 \\
\hline & $\begin{array}{l}\text { Китайцы } \\
\text { Chinese }\end{array}$ & 4,13 & 5,31 & 4,38 \\
\hline & $\begin{array}{l}\text { Азербайлжанцы } \\
\text { Azerbaijanians }\end{array}$ & 4 & 4,58 & 5,25 \\
\hline & $\begin{array}{l}\text { Узбеки } \\
\text { Uzbeks }\end{array}$ & 3,88 & 4,78 & 4,38 \\
\hline & $\begin{array}{l}\text { Taтapы } \\
\text { Tatars }\end{array}$ & 3,63 & 5,04 & 4,25 \\
\hline & $\begin{array}{l}\text { Армяне } \\
\text { Armenians }\end{array}$ & 2,38 & 3,78 & 4,38 \\
\hline & $\begin{array}{l}\text { Буряты } \\
\text { Buryats }\end{array}$ & 3,63 & 3,37 & 3,69 \\
\hline & $\begin{array}{l}\text { Украинцы } \\
\text { Ukrainians }\end{array}$ & 2,62 & 3,68 & 4,88 \\
\hline & $\begin{array}{l}\text { Белорусы } \\
\text { Byelorussians }\end{array}$ & 3,88 & 3,02 & 4 \\
\hline & $\begin{array}{l}\text { Русские } \\
\text { Russians }\end{array}$ & 1,13 & 1,33 & 1,3 \\
\hline \multirow{6}{*}{$\begin{array}{l}\text { Этническая } \\
\text { илентичность } \\
\text { Ethnic identity }\end{array}$} & $\begin{array}{l}\text { Позитивная этническая } \\
\text { илентичность } \\
\text { Positive ethnic identity }\end{array}$ & $17,6^{*}$ & $14,88^{*}$ & $12,8^{*}$ \\
\hline & $\begin{array}{l}\text { Индиорорерентность } \\
\text { Indifference }\end{array}$ & 11,13 & 10,62 & 11 \\
\hline & $\begin{array}{l}\text { Этнофранатизм } \\
\text { Ethno-fanaticism }\end{array}$ & $8,13^{*}$ & 10,35 & $12,8^{*}$ \\
\hline & $\begin{array}{l}\text { Этноизоляционизм } \\
\text { Ethno-isolationism }\end{array}$ & 7,13 & 7,88 & 9,4 \\
\hline & $\begin{array}{l}\text { Этноэгоизм } \\
\text { Ethno-egoism }\end{array}$ & $5,88^{*}$ & 8,73* & $11,6^{*}$ \\
\hline & $\begin{array}{l}\text { Этнонигилизм } \\
\text { Ethno-nihilism }\end{array}$ & $5,88^{*}$ & 6,15 & $7,62^{*}$ \\
\hline
\end{tabular}




\begin{tabular}{|c|c|c|c|c|}
\hline \multirow{2}{*}{$\begin{array}{c}\text { Критерии } \\
\text { Criteria }\end{array}$} & \multirow{2}{*}{$\begin{array}{c}\text { Показатели } \\
\text { Characteristics }\end{array}$} & \multicolumn{3}{|c|}{$\begin{array}{l}\text { Средние значения } \\
\text { Mean Scores }\end{array}$} \\
\hline & & $I$ & II & III \\
\hline \multirow{10}{*}{$\begin{array}{l}\text { Индиви- } \\
\text { дуальные } \\
\text { ценностные } \\
\text { ориентации } \\
\text { Individual value } \\
\text { orientations }\end{array}$} & $\begin{array}{l}\text { Универсализм } \\
\text { Universalism }\end{array}$ & $5,68^{*}$ & 5,29 & $3,8^{*}$ \\
\hline & $\begin{array}{l}\text { Самостоятельность } \\
\text { Independence }\end{array}$ & 5,38 & 5,28 & 4,55 \\
\hline & $\begin{array}{l}\text { Безопасность } \\
\text { Safety }\end{array}$ & 5,25 & 5,26 & 4,35 \\
\hline & $\begin{array}{l}\text { Благожелательность } \\
\text { Benevolence }\end{array}$ & 5,18 & 4,87 & 4,34 \\
\hline & $\begin{array}{l}\text { Стимуляция } \\
\text { Stimulation }\end{array}$ & 4,69 & 4,65 & 3,64 \\
\hline & $\begin{array}{l}\text { Аостижения } \\
\text { Achievement }\end{array}$ & 4,66 & 4,49 & 4,5 \\
\hline & $\begin{array}{l}\text { Конорормность } \\
\text { Conformity }\end{array}$ & 4,46 & 4,83 & 3,19 \\
\hline & $\begin{array}{l}\text { Традиции } \\
\text { Traditions }\end{array}$ & 4,05 & 4,2 & 3,08 \\
\hline & $\begin{array}{l}\text { ГеАонизм } \\
\text { Hedonism }\end{array}$ & 3,68 & 3,82 & 4,28 \\
\hline & $\begin{array}{l}\text { B^actb } \\
\text { Power }\end{array}$ & 3 & 3 & 4,09 \\
\hline
\end{tabular}

Примечание: * достоверность различий по U-критерию Манна - Уитни прир $<0,05$; ** nрир $<0,01$. The Mann-Whitney $U$ test: ${ }^{*}$ at the $p<0.05$ significance level; ${ }^{* *}$ at the $p<0.01$ significance level.

Описывая приведенные в этой таблице данные, следует отметить, что подростки с высоким уровнем толерантности (группа I) отличаются положительным отношением к представителям других этнических групп (p <0,01), выраженным позитивным типом этнической идентичности ( $p<0,05)$, ориентацией на ценности универсализма $(p<0,05)$. Респонденты со средним уровнем толерантности (группа II) также обладают позитивным типом этнической идентичности, но с тенденцией к размыванию этнической идентичности, ее неактуальности, более высокими показателями по шкале этноэгоизма ( $p<0,05)$, свидетельствующей о наличии напряженности и даже раздражения по отношению к представителям других этнических групп. Толерантность к Другим носит избирательный и ситуативный характер. У подростков с низким уровнем толерантности мы наблюдаем рост 


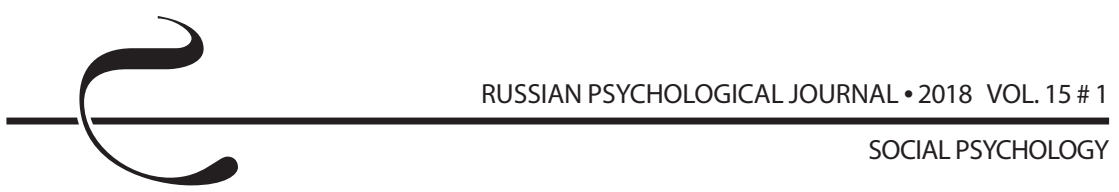

социальной дистанции, этнофанатизма ( $\mathrm{p}<0,05)$, этноизоляционизма, этноэгоизма $(p<0,05)$, значения ценностей гедонизма и власти.

\section{Обсуждение результатов}

Полученные в исследовании результаты в целом подтверждают выдвинутую нами гипотезу о наличии определенных негативных тенденций в этнической социализации современных подростков. Несмотря на то, что доминирующим типом этнической идентичности опрошенных подростков является позитивная этническая идентичность, заключающаяся в принятии своей этнокультурной принадлежности в сочетании с положительным отношением к другим этническим группам, мы наблюдаем тенденцию к ее нивелированию или гиперболизации. Полученные результаты согласуются с исследованиями, указывающими на изменения этнической идентичности современных подростков по типу гипоидентичности, проявляющейся в ее неактуальности и неопределенности, или, что в большей степени настораживает, склонности к гиперидентичности (этнофанатизму), которая, как отмечает Г.У. Солдатова, является основой этнической нетерпимости [4].

Вышесказанное подтверждается выраженной социальной дистанцией подростков к другим этническим группам. Мы предполагаем, что отчужденность подростков по отношению к некоторым этническим группам обусловлена редкими контактами с их представителями с одной стороны, а также, с другой стороны, наличием предубежденности и негативных стереотипов, снижением значимости ценностей универсализма. Эмпирические данные свидетельствуют об озабоченности подростков, прежде всего, безопасностью себя и своих близких, их стремлении к стабильности в обществе и взаимоотношениях. Они в целом благожелательно настроены по отношению к различным этническим группам, но, тем не менее, ценности универсализма, поддержки традиций, культурных обычаев не представляются важными. Полученные данные подтверждают исследования, согласно которым современные подростки стремятся быть образованными, успешными, внешне привлекательными, а культурные и нравственные ценности не находят у них должной оценки $[29,30]$. При этом опрошенные подростки проявляют избирательную толерантность в межэтнических отношениях.

Опираясь на выявленные особенности этнической социализации испытуемых, мы смогли выделить три варианта этнической социализации подростков. Первый вариант этнической социализации характерен для подростков, отличающихся высоким уровнем толерантности, выраженной позитивной идентичностью, отсутствием предубежденности и негативных этнических стереотипов, ценностным отношением к этническому разнообразию, что, по нашему мнению, можно характеризовать как успешную этническую социализацию. 
Второй вариант этнической социализации присущ подросткам, имеющим менее выраженную позитивную этническую идентичность с тенденцией к ее индифферентности, избирательным в межэтнических отношениях, обладающим ситуативной толерантностью. Данный вариант обозначен нами как незавершенная этническая социализация. Обращает на себя внимание третий вариант этнической социализации подростков, отличающихся тенденцией к гиперболизации этнической идентичности (этнофанатизму) и интолерантно настроенных. В связи с тем, что этнофанатизм предполагает готовность идти на любые, даже противоправные действия по отношению к представителям других национальностей, данный вариант этнической социализации можно интерпретировать как этническую десоциализацию.

\section{Заключение}

Проведенное исследование позволяет сделать ряд выводов:

1. Эмпирические данные свидетельствуют о том, что большинство опрошенных подростков обладают средним индексом толерантности, позитивной этнической идентичностью, ориентацией на ценности безопасности и стабильности в обществе.

2. Негативными тенденциями и рисками этнической социализации подростков выступают: склонность к размыванию или, наоборот, к гиперболизации этнической идентичности; наличие выраженной социальной дистанции к представителям ряда этнических групп; присутствие негативных этнических стереотипов.

3. Необходимо выделить три варианта этнической социализации опрошенных подростков:

1) для успешной этнической социализации характерны: положительное оценивание себя, идеала, представителей своей национальности при положительном оценивании представителей другой этнической группы; позитивная идентификация со своим народом; развитая толерантность, значимость ценности универсализма;

2) второй вариант этнической социализации подростков, обозначаемый как незавершенный, характеризуется ситуативной толерантностью, тенденцией к снижению позитивного отношения к представителям других этнических групп, неопределенностью, неактуальностью этнической идентичности; при отсутствии негативных этнических стереотипов представители других этнических групп оцениваются ниже, чем свои, отмечается избирательность по отношению к ним.

3) третий вариант этнической социализации определяется как этническая десоциализация, т. к. присутствуют интолерантность, тенденция к этнофанатизму, предубежденность по отношению к другим этническим группам. 


\section{Литература}

1. Выготский Л. С. Психология развития. Избранные работы. - М. : Юрайт, 2017. - 302 c.

2. Белинская Е. П., Стефаненко Т.Г. Этническая социализация подростка. М. : МПСИ ; Воронеж : МОДЭК, 2000. - 208 с.

3. Стефаненко Т. Г. Этническая идентичность: от этнологии к социальной психологии // Вестник Московского университета. Серия 14. Психология. - 2009. - № 2. - С. 3-17.

4. Солдатова Г. У., Шайгерова Л. А., Шарова О.Д. Жить в мире с собой и другими: тренинг толерантности для подростков. - М. : Генезис, 2001. - 2-е изд. - 112 с.

5. Темирова Ф.А. Психологические особенности формирования этнической толерантности подростков в образовательном процессе школы : дисс. ... канд. психол. наук. - Курск, 2007. - 184 с.

6. Федорова С. Н. Этнокультурное развитие детей. Психолого-педагогическое сопровождение : учебное пособие. - М. : Форум, 2011. $176 \mathrm{c}$.

7. Хотинец В. Ю., Молчанова Е. А. Опосредующая роль этнического образа в межэтнических отношениях // Психологический журнал. - 2014. - Т. 35, № 3. - C. 40-57.

8. Хотинец В. Ю. Особенности виктимизации подростков в условиях дефицитарности инкультурации // На перекрестке миграции: от теоретических моделей к практическим решениям. Сборник материалов четвертой Всероссийской научно-практической конференции «Практическая этнопсихология: актуальные проблемы и перспективы развития» (г. Москва, 25-26 октября 2013 г.) / под ред. О. Е. Хухлаева. - М. : Изд-во МГППУ, 2013. C. 102-103. - URL: http://psyjournals.ru/files/63461/ethnoconf_2013_tezis. PDF (дата обращения: 19.02.2018).

9. Гришина А. В., Лунин С. Л. Типы этнической идентичности российской молодежи как показатель позитивной готовности к принятию вынужденных мигрантов из Украины // Российский психологический журнал. - 2015. - Т. 12, № 2. - С. 46-55.

10. Bennett M. J. Becoming interculturally competent // Toward multiculturalism: A reader in multicultural education / J. Wurzel (Ed.). - Newton, MA : Intercultural Resource Corporation, 2004. - 2nd ed. - P. 62-77. - URL: http:// www.emic-project.org/wp-content/uploads/2015/10/BecomingInterculturallyCompetent_Bennett.pdf (дата обращения: 19.02.2018).

11. Brown C. M., Ling W. Ethnic-Racial Socialization Has an Indirect Effect on SelfEsteem for Asian American Emerging Adults // Psychology. - 2012. - Vol. 3, № 1. - P. 78-81. DOI: 10.4236/psych.2012.31013 
12. Chung A. Y. From Caregivers to Caretakers: The Impact of Family Roles on Ethnicity Among Children of Korean and Chinese Immigrant Families // Qualitative Sociology. - 2013. - Vol. 36, Issue 3. - P. 279-302. DOI: 10.1007/s11133-013-9252-x

13. Csizmadia A., Rollins A., Kaneakua J. P. Ethnic-Racial Socialization and Its Correlates in Families of Black-White Biracial Children // Family Relations. 2014. - Vol. 63, Issue 2. - P. 259-270. DOI: 10.1111/fare.12062

14. Hernández M. M., Conger R. D., Robins R. W., Bacher K. B., Widaman K. F. Cultural Socialization and Ethnic Pride Among Mexican-Origin Adolescents During the Transition to Middle School // Child Development. - 2014. - Vol. 85, Issue 2. - P. 695-708. DOI: 10.1111/cdev.12167

15. Эриксон Э. Идентичность: юность и кризис. - М. : Флинта, МПСИ, Прогресс, 2006. - 2-е изд. Серия: Библиотека зарубежной психологии. - 352 с.

16. Бучек А. А. Этническое самосознание личности в пространстве полиэтнического мира : монография. - Петропавловск-Камчатский : Изд-во КамГУ им. Витуса Беринга, 2012. - 386 с.

17. Grimm J., Huddy L., Schmidt P., Seethaler J. Dynamics of National Identity: Media and Societal Factors of What We Are. - New York: Routledge, 2016. - 356 p.

18. Phinney J. S. Ethnic identity in adolescents and adults: Review of research // Psychological Bulletin. - 1990. - Vol. 108 (3). - P. 499-514. DOI: 10.1037/00332909.108.3.499

19. Umaña-Taylor A. J., Quintana S. M., Lee R. M., et al. Ethnic and Racial Identity During Adolescence and Into Young Adulthood: An Integrated Conceptualization // Child Development. - 2014. - Vol. 85, Issue 1. - P. 21-39. DOI: 10.1111/cdev.12196

20. Корниенко Д. С., Гайдамашко И. В., Кандыбович С. Л. Динамика этнической идентичности студентов коми-пермяков и русских в процессе обучения // Российский психологический журнал. - 2017. - Т. 14, № 1. C. 108-123. DOI: 10.21702/rpj.2017.1.7

21. Јовановић Б., Качапор С. Васпитање за међунационалну толеранцију и сарадњу // TEME. - 2016. - г. XL, 6p. 1. - С. 351-364. - URL: https://www.

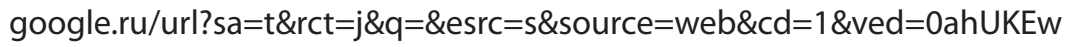
ix2of59XZAhUJDywKHQxzBr8QFggqMAA\&url=http\%3A\%2F\%2Fteme2. junis.ni.ac.rs\%2Findex.php\%2FTEME\%2Farticle\%2Fdownload\%2F25\%2F1 14\&usg=AOvVaw0hdQmfU9jBJPbL7ijFr6zR (дата обращения: 19.02.2018).

22. Verkuyten M. Further Conceptualizing Ethnic and Racial Identity Research: The Social Identity Approach and Its Dynamic Model // Child Development. - 2016. - Vol. 87, Issue 6. - P. 1796-1812. DOI: 10.1111/cdev.12555

23. Лебедева Н. М., Татарко А. Н., Берри Дж. Социально-психологические основы мультикультурализма: проверка гипотез о межкультурном 


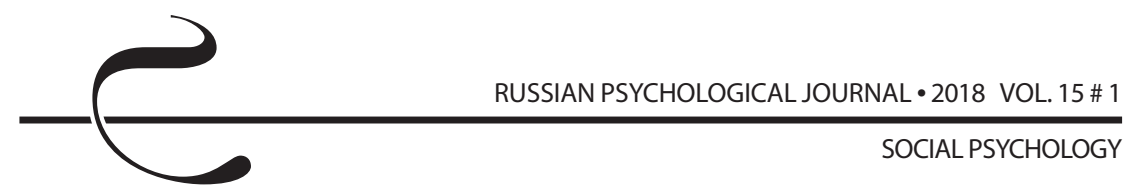

взаимодействии в российском контексте // Психологический журнал. 2016. - T. 37, № 2. - C. 92-104.

24. Combs G. M., Milosevic I., Jeung W., Griffith J. Ethnic Identity and Job Attribute Preferences: The Role of Collectivism and Psychological Capital // Journal of Leadership \& Organizational Studies. - 2012. - Vol. 19, Issue 1. - P. 5-16. DOI: $10.1177 / 1548051811433359$

25. Costigan C. L., Koryzma C. M., Hua J. M., Chance L. J. Ethnic identity, achievement, and psychological adjustment: Examining risk and resilience among youth from immigrant Chinese families in Canada // Cultural Diversity and Ethnic Minority Psychology. - 2010. - Vol. 16 (2). - P. 264-273. DOI: 10.1037/ a0017275

26. Johnson L. R., Kim E. H., Johnson-Pynn J. S., Schulenberg S. E., Balagaye H., Lugumya D. Ethnic Identity, Self-Efficacy, and Intercultural Attitudes in East African and U.S. Youth // Journal of Adolescent Research. - 2012. - Vol. 27, Issue 2. - P. 256-289. DOI: 10.1177/0743558411412955

27. Абакумова И. В., Брижак 3. И., Масаева 3. В. Особенности агрессивного поведения школьников разной этнической принадлежности в условиях постконфликтного региона // Российский психологический журнал. 2016. - T. 13, № 4. - C. 100-116. DOI: 10.21702/rpj.2016.4.6

28. Inglehart R., Baker W. E. Modernization, Cultural Change, and the Persistence of Traditional Values // American Sociological Review. - 2000. - Vol. 65, № 1. - P. 19-51. DOI: 10.2307/2657288

29. Фельдштейн Д. И. Глубинные изменения современного Детства и обусловленная ими актуализация психолого-педагогических проблем развития образования // Известия Российской академии образования. - 2011. - № 4. - С. 5-24.

30. Лебедева Н. М., Татарко А. Н. Культура как фактор общественного прогресса. - М. : Юстицинформ, 2009. - 408 с.

\section{References}

1. Vygotskii L. S. Psikhologiya razvitiya. Izbrannye raboty [Developmental psychology: Selected works]. Moscow, Yurait Publ., 2017. 302 p.

2. Belinskaya E. P., Stefanenko T. G. Etnicheskaya sotsializatsiya podrostka [An adolescent's ethnic socialization]. Voronezh, MODEK Publ., 2000. 208 p.

3. StefanenkoT. G. Ethnic identity: From ethnology to social psychology. Vestnik Moskovskogo universiteta. Seriya 14. Psikhologiya - The Moscow University Herald. Series 14. Psychology, 2009, no. 2, pp. 3-17 (in Russian).

4. Soldatova G. U., Shaigerova L. A., Sharova O. D. Zhit' v mire s soboi i drugimi: trening tolerantnosti dlya podrostkov [Living in peace with yourself and others: Tolerance training for adolescents]. Moscow, Genezis Publ., 2001. 112 p. 
5. Temirova F. A. Psikhologicheskie osobennosti formirovaniya etnicheskoi tolerantnosti podrostkov $v$ obrazovatel'nom protsesse shkoly [Psychological features of adolescents' ethnic tolerance in the school educational process]. Diss. Cand. Sci. (Psych.). Kursk, 2007. 184 p.

6. Fedorova S. N. Etnokul'turnoe razvitie detei. Psikhologo-pedagogicheskoe soprovozhdenie [Ethno-cultural development of children: Psycho-pedagogical support]. Moscow, Forum Publ., 2011. 176 p.

7. Khotinets V. Yu., Molchanova E. A. The mediating role of an ethnic image in interethnic relations. Psikhologicheskii zhurnal, 2014, V. 35, no. 3, pp. 40-57 (in Russian).

8. Khotinets V. Yu. Adolescents' victimization in the conditions of the deficiency of inculturation. In: Khukhlaeva E. (ed.) Na perekrestke migratsii: ot teoreticheskikh modelei $k$ prakticheskim resheniyam [At the crossroads of migration: From theoretical models to practical solutions]. Moscow, MGPPU Publ., 2013, pp. 102-103. Available at: http://psyjournals.ru/files/63461/ ethnoconf_2013_tezis.PDF (Accessed 19 February 2018).

9. Grishina A. V., Lunin S. L. Types of ethnic identity in Russian young people as the indicator of positive readiness for forced migrants from Ukraine. Rossiiskii psikhologicheskii zhurnal - Russian Psychological Journal, 2015, V. 12, no. 2, pp. 46-55 (in Russian).

10. Bennett M. J. Becoming interculturally competent. In: J. Wurzel (ed.) Toward multiculturalism: A reader in multicultural education. Newton, MA, Intercultural Resource Corporation, 2004, pp. 62-77. Available at: http://www. emic-project.org/wp-content/uploads/2015/10/BecomingInterculturallyCompetent_Bennett.pdf (Accessed 19 February 2018).

11. Brown C. M., Ling W. Ethnic-racial socialization has an indirect effect on self-esteem for Asian American emerging adults. Psychology, 2012, V. 3, no. 1, pp. 78-81. DOI: 10.4236/psych.2012.31013

12. Chung A. Y. From caregivers to caretakers: The impact of family roles on ethnicity among children of Korean and Chinese immigrant families. Qualitative Sociology, 2013, V. 36, Issue 3, pp. 279-302. DOI: 10.1007/s11133-013-9252-x

13. Csizmadia A., Rollins A., Kaneakua J. P. Ethnic-racial socialization and its correlates in families of black-white biracial children. Family Relations, 2014, V. 63, Issue 2, pp. 259-270. DOI: 10.1111/fare.12062

14. Hernández M. M., Conger R. D., Robins R. W., Bacher K. B., Widaman K. F. Cultural socialization and ethnic pride among Mexican-origin adolescents during the transition to middle school. Child Development, 2014, V. 85, Issue 2, pp. 695-708. DOI: 10.1111/cdev.12167

15. Erikson E. Identity:youth and crisis (Russ. ed.: Erikson E. Identichnost': yunost' i krizis. Moscow, Flinta, MPSI, Progress Publ., 2006. 352 p.). 
16. Buchek A. A. Etnicheskoe samosoznanie lichnosti v prostranstve polietnicheskogo mira [Ethnic self-consciousness in the polyethnic space]. PetropavlovskKamchatskiy, Kamchatka State University Publ., 2012. 386 p.

17. Grimm J., Huddy L., Schmidt P., Seethaler J. Dynamics of national identity: Media and societal factors of what we are. New York, Routledge, 2016. 356 p.

18. Phinney J. S. Ethnic identity in adolescents and adults: Review of research. Psychological Bulletin, 1990, V. 108 (3), pp. 499-514. DOI: 10.1037/00332909.108.3.499

19. Umaña-Taylor A. J., Quintana S. M., Lee R. M., et al. Ethnic and racial identity during adolescence and into young adulthood: An integrated conceptualization. Child Development, 2014, V. 85, Issue 1, pp. 21-39. DOI: 10.1111/ cdev.12196

20. Kornienko D. S., Gaidamashko I. V., Kandybovich S. L. Dynamics of ethnic identity in the Komi-Perm and Russian students in the educational process. Rossiiskii psikhologicheskii zhurnal - Russian Psychological Journal, 2017, V. 14, no. 1, pp. 108-123 (in Russian). DOI: 10.21702/rpj.2017.1.7

21. Jovanović B., Kačapor S. Role of education in developing inter-ethnic tolerance and cooperation. Teme, 2016, pp. 351-364. URL: https://www.google. $\mathrm{ru} / \mathrm{url}$ ?sa $=\mathrm{t} \& \mathrm{rct}=\mathrm{j} \& \mathrm{q}=\&$ esrc $=\mathrm{s} \&$ source $=$ web\&cd $=1 \& \mathrm{ved}=0$ ahUKEwix 2 of 59 XZAhUJDywKHQxzBr8QFggqMAA\&url=http\%3A\%2F\%2Fteme2.junis.ni.ac. rs\%2Findex.php\%2FTEME\%2Farticle\%2Fdownload\%2F25\%2F114\&usg=A OvVaw0hdQmfU9jBJPbL7ijFr6zR (Accessed 19 February 2018).

22. Verkuyten $M$. Further conceptualizing ethnic and racial identity research: The social identity approach and its dynamic model. Child Development, 2016, V. 87, Issue 6, pp. 1796-1812. DOI: 10.1111/cdev.12555

23. Lebedeva N. M., Tatarko A. N., Berry J. Socio-psychological foundations of multiculturalism: Testing the hypothesis on cross-cultural interaction in the Russian context. Psikhologicheskiizhurnal, 2016,V.37, no. 2, pp.92-104 (in Russian).

24. Combs G. M., Milosevic I., Jeung W., Griffith J. Ethnic identity and job attribute preferences: The role of collectivism and psychological capital. Journal of Leadership \& Organizational Studies, 2012, V. 19, Issue 1, pp. 5-16. DOI: $10.1177 / 1548051811433359$

25. Costigan C. L., Koryzma C. M., Hua J. M., Chance L. J. Ethnic identity, achievement, and psychological adjustment: Examining risk and resilience among youth from immigrant Chinese families in Canada. Cultural Diversity and Ethnic Minority Psychology, 2010, V. 16 (2), pp. 264-273. DOI: 10.1037/a0017275

26. Johnson L. R., Kim E. H., Johnson-Pynn J. S., Schulenberg S. E., Balagaye H., Lugumya D. Ethnic identity, self-efficacy, and intercultural attitudes in East African and U.S. youth. Journal of Adolescent Research, 2012, V. 27, Issue 2, pp. 256-289. DOI: 10.1177/0743558411412955 
27. Abakumova I. V., Brizhak Z. I., Masaeva Z. V. Aggressive behavior among schoolchildren belonging to various ethnic groups in a post-conflict region. Rossiiskii psikhologicheskii zhurnal - Russian Psychological Journal, 2016, V. 13, no. 4, pp. 100-116 (in Russian). DOI: 10.21702/rpj.2016.4.6

28. Inglehart R., Baker W. E. Modernization, cultural change, and the persistence of traditional values. American Sociological Review, 2000, V. 65, no. 1, pp. 19-51. DOI: 10.2307/2657288

29. Fel'dshtein D. I. Profound changes in modern childhood and psychopedagogical problems of education development. Izvestiya Rossiiskoi akademii obrazovaniya - Bulletin of the Russian Academy of Education, 2011, no. 4, pp. 5-24 (in Russian).

30. Lebedeva N. M., Tatarko A. N. Kul'tura kak faktor obshchestvennogo progressa [Culture as a factor of social progress]. Moscow, Yustitsinform Publ., 2009. 408 p. 